\title{
Matrine induces the apoptosis of lung cancer cells through downregulation of inhibitor of apoptosis proteins and the Akt signaling pathway
}

\author{
HUIYAN NIU, YIFEI ZHANG, BAOGANG WU, YI ZHANG, HONGFANG JIANG and PING HE \\ Department of Geriatrics, Shengjing Hospital, China Medical University, Shenyang 110004, P.R. China
}

Received March 5, 2014; Accepted May 13, 2014

DOI: $10.3892 /$ or.2014.3273

\begin{abstract}
Lung cancer is the leading cause of cancer-related mortality in humans. The prognosis for advanced lung cancer patients is extremely poor. Current standard care is rather ineffective for prolonging patient life while preserving satisfactory quality of life due to adverse side-effects. Matrine extracted from the traditional Chinese herbal plant Sophora flavescens was shown to induce cancer cell death in vitro. The aim of this study was to investigate the effect of matrine on the proliferation and apoptosis of lung cancer cells and the molecular basis of matrine-induced apoptosis. The results showed that matrine inhibited cell proliferation and induced apoptosis in lung cancer A549 and 95D cells in a dose- and time-dependent manner. The apoptotic effects of matrine on lung cancer cells appeared to act via the phosphatidylinositol 3-kinase/Akt/mammalian target of rapamycin (PI3K-Akt-mTOR) signaling pathway and downregulation of the expression of the inhibitor of apoptosis protein (IAP) family proteins. Matrine exerts its cancer-killing effect via promoting apoptosis in lung cancer cells and may be a useful adjuvant therapeutic scheme for treating advanced lung cancer patients.
\end{abstract}

\section{Introduction}

Lung cancer is the leading cause of cancer-related mortality in humans, and is attributed to the death of more than 1 million individuals each year. New cases of lung cancer account for $13 \%$ ( 1.6 million) of the total new cancer cases diagnosed each year (1). In China, many of these new cases of lung cancer often exhibit malignant characteristics such as multiple tumor

Correspondence to: Dr Ping He, Department of Geriatrics, Shengjing Hospital, China Medical University, 36 Sanhao Street, Heping, Shenyang 110004, P.R. China

E-mail: hep@sj-hospital.org

Key words: matrine, lung cancer, apoptosis, inhibitors of apoptosis proteins, phosphatidylinositol 3-kinase/Akt/mammalian target of rapamycin sites and high propensity to metastasize (2). Despite recent advances in the development of multidisciplinary treatment regimens for lung cancer, the prognosis of lung cancer patients remains poor and the 5-year survival rate is only $\sim 15 \%$ (3).

Approximately 85 to $90 \%$ of lung cancer cases are non-small cell lung cancer (NSCLC), which includes three major subtypes: squamous cell (epidermoid) carcinoma (25-30\%), adenocarcinoma (40\%) and large cell (undifferentiated) carcinoma (10-15\%). While there exist discernible differences in size, shape and chemical make-up between these three subtypes, the clinical approaches to treatment and prognosis are often very similar. The standard treatments for patients presenting with advanced stages of lung cancer are chemotherapy and radiotherapy. However, these therapies often bring only marginal benefits in regards to patient survival; the median survival time after receiving chemotherapy is $<1$ year. As normal cells are also adversely affected by these therapies, the treatment is often accompanied by undesirable side-effects, which, along with the limited improvement in patient survival, results in the poor quality of life for lung cancer patients receiving standard care. Novel therapeutics with higher specificity towards cancer cells and less toxicity are urgently needed for treating lung cancer patients.

Small chemicals extracted from plants, recognized for low toxicity and often better bioavailability than synthetic drugs, have become a hotspot in the search for novel drugs. In particular, herbs used in Traditional Chinese Medicine (TCM) are gaining wider recognition in recent years as an underexploited source for potential therapeutic compounds $(4,5)$. Matrine (Fig. 1) is an alkaloid extracted as the major active ingredient of the traditional Chinese herb Sophora flavescens Ait. (6). Presently, there are over 300 commercial concoctions containing matrine or its derivative oxymatrine in the database of drug manufacturing licenses approved by the China Food and Drug Administration (http://www.sda.gov. $\mathrm{cn} /$ ). These drug preparations have been prescribed for the treatment of cancer, arrhythmia (7-9), viral hepatitis (10-12), hepatic fibrosis (13) and skin diseases such as atopic dermatitis and eczema (14). In the past few years, a growing body of evidence suggests that matrine and oxymatrine may have some promising potential in cancer treatment as demonstrated by their tumoricidal effects on many cancer cell lines including those derived from gastric cancer, cervical cancer, leukemia, 
hepatocellular carcinoma, breast cancer, pancreatic cancer and lung cancer $(3,15-25)$. The major mechanisms that have been postulated to underlie the antitumor effects of matrine center on the regulation of apoptosis- and proliferation-related genes and proteins, such as Bcl-2 family members, caspases, E2F-1, Akt and Fas/FasL (23,26-29).

Although available data suggest that the cytotoxic effect of matrine may be wide-spectrum against multiple types of cancer cells, it has not been thoroughly documented whether and how matrine may affect the growth of different types of lung cancer cells. In this study, we investigated the effect of matrine on two highly invasive lung cancer cell lines, A549 and 95D. Our results indicated that matrine is mildly effective in killing both of these types of lung cancer cells, suggesting that matrine may be more useful as an adjuvant therapy in combination with other treatments of lung cancer. Furthermore, our results suggest that matrine exerts its cancer-killing effect via promoting apoptosis in lung cancer cells, possibly through the downregulation of cIAPs and the Akt signaling pathway.

\section{Materials and methods}

Therapeutic compounds and reagents. Lung cancer cell lines A549 and 95D were purchased from the Shanghai Institute of Biochemistry and Cell Biology, Chinese Academy of Sciences. Matrine was purchased from the National Institute for the Control of Pharmaceutical and Biological Products (Beijing, China). DMSO and MTT were purchased from Sigma (St. Louis, MO, USA). Annexin V-FITC apoptosis detection kit was from KeyGene (Nanjing, China). RPMI tissue culture medium and fetal bovine serum (FBS) were purchased from Gibco (USA). Anti-survivin, anti-cIAP1, anti-cIAP2, anti-Smac, anti-Akt, anti-p-Akt, anti-GAPDH and HRP-conjugated secondary antibodies were purchased from Abcam Biotechnology (USA). Chemiluminescence (ECL) reagent kit was purchased from Pierce Biotechnology (Rockford, IL, USA).

Cell culture. A549 and 95D cells were cultured in RPMI-1640 medium containing 10\% FBS, $100 \mathrm{IU} / \mathrm{ml}$ penicillin and $100 \mu \mathrm{g} / \mathrm{ml}$ streptomycin. The cells were grown in a humidified incubator at $37^{\circ} \mathrm{C}$ in an atmosphere of $5 \% \mathrm{CO}_{2}$ in air. Cells were grown on sterile tissue culture Petri dishes and passaged once every 2 to 3 days.

MTT cell viability assay. Cells were seeded in a 96-well plate at a density of $1 \times 10^{5} / \mathrm{ml}$ and cultured in medium overnight. Cell viability was determined using the conversion of MTT to formazan via mitochondrial oxidation. Various treatments of cells included the addition of matrine $(0,0.25,0.5,1.0,1.5$ and $2.0 \mathrm{~g} / \mathrm{l}$ ) for 12,24 and $48 \mathrm{~h}$. MTT solution was then added to each well at a final concentration of $1 \mathrm{mg} / \mathrm{ml} /$ well, and the plates were incubated at $37^{\circ} \mathrm{C}$ for another $4 \mathrm{~h}$. After incubation, $150 \mu \mathrm{l}$ DMSO was added to each well to dissolve the formazan formed, and the absorbance was read at $490 \mathrm{~nm}$ using a spectrophotometer.

Flow cytometric assay of apoptosis. Cellular apoptosis was determined using the Annexin V-FITC and propidium iodide

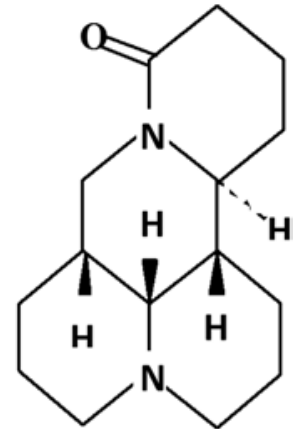

Figure 1. Chemical structure of matrine $\left(\mathrm{C}_{15} \mathrm{H}_{24} \mathrm{~N}_{20}, \mathrm{MW}=248.37\right)$.

(PI) double staining kit according to the manufacturer's protocol with minor modification. Briefly, A549 cells were seeded in 6-well plates and allowed to attach overnight; matrine $(0,0.25,0.5,1.0,1.5$ and $2.0 \mathrm{~g} / \mathrm{l})$ was then added to the medium, and cells were incubated for $48 \mathrm{~h}$. Cells were harvested, washed twice with cold PBS, resuspended in $250 \mu \mathrm{l}$ of binding buffer and stained with a staining solution containing Annexin V/FITC and PI. After incubation in the dark for $30 \mathrm{~min}$, cells were analyzed by FACSCalibur flow cytometry (BD Biosciences, USA).

Fluorescence microscopy. A549 cells were treated with a $1.0 \mathrm{~g} / \mathrm{l}$ concentration of matrine for $48 \mathrm{~h}$. Cells were washed twice with PBS and fixed with cold methanol and acetic acid before being stained with Hoechst 33342 for $30 \mathrm{~min}$ in the dark. Stained cells were observed with a fluorescence microscope (Nikon, Japan).

Western blotting. Western blotting was performed using standard techniques as previously described (30,31). Generally, cells were washed twice with PBS buffer and lysed in RIPA lysis buffer (50 mM Tris- $\mathrm{Cl} \mathrm{pH} 7.4,150 \mathrm{mM} \mathrm{NaCl}$, $0.5 \%$ sodium deoxycholate, $1 \%$ NP-40, $0.1 \%$ SDS, $1 \mathrm{mM}$ EDTA, $100 \mathrm{mM} \mathrm{NaF}, 1 \mathrm{mM} \mathrm{Na} \mathrm{VO}_{4}, 1 \mathrm{mM}$ PMSF and $2 \mu \mathrm{g} / \mathrm{ml}$ aprotinin) on ice. Total proteins $(50 \mu \mathrm{g})$ were subjected to sodium dodecyl sulfate-polyacrylamide gel electrophoresis (SDS-PAGE) and transferred to polyvinylidene difluoride (PVDF) membranes. The PVDF membranes were blocked with $5 \%$ nonfat milk in TBST (10 mM Tris, $\mathrm{pH} 7.4$, $150 \mathrm{mM} \mathrm{NaCl}$ and $0.1 \%$ Tween-20) at room temperature for $2 \mathrm{~h}$ and incubated with the indicated primary antibodies at $4^{\circ} \mathrm{C}$ overnight with gentle rocking. After washing with TBST, the membranes were reacted with appropriate horseradish peroxidase (HRP)-conjugated secondary antibodies for $1 \mathrm{~h}$ at room temperature. After extensive washing with TBST, the presence of proteins was visualized by the enhanced chemiluminescence (ECL) detection kit in accordance with the manufacturer's recommendations.

Statistical analysis. Each experiment involving tissue culture was performed in triplicates. All analyses were performed using the SPSS 13.0 software. Results are expressed as mean \pm SD. The one-way analysis of variance (ANOVA) was used to compare the difference between treatment groups. Differences were considered significant at a $\mathrm{P}$-value $<0.05$. 

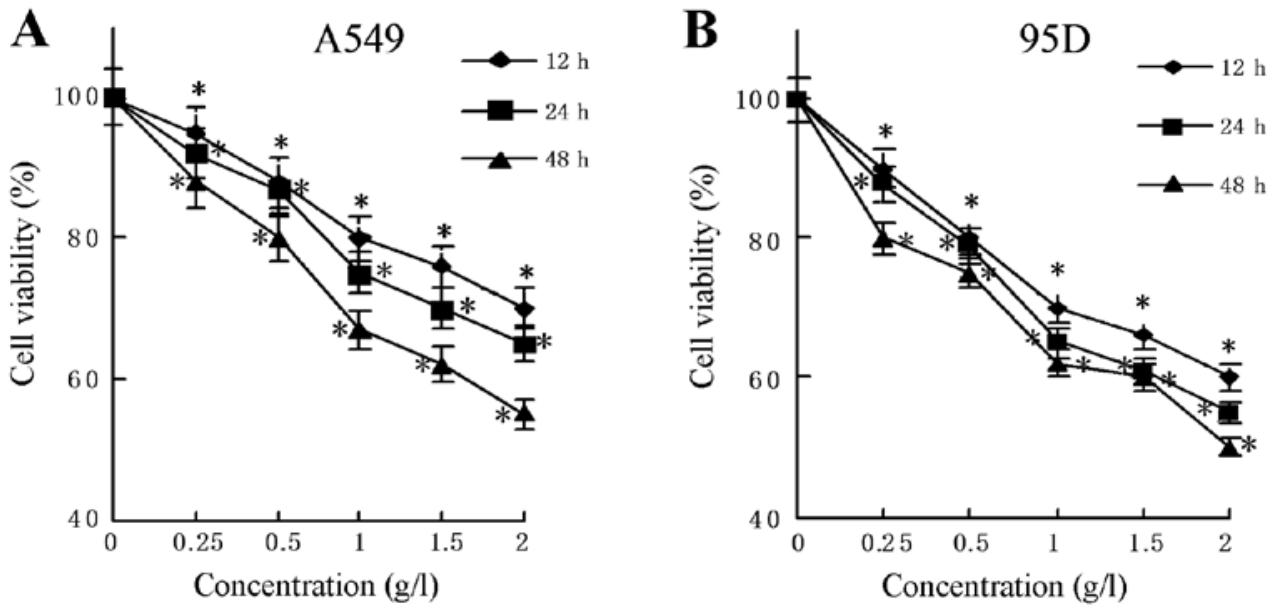

Figure 2. Matrine inhibits the growth of A549 and 95D cells in vitro. A549 and 95D cells were treated with 0, 0.25, 0.5, 1.0, 1.5 and $2.0 \mathrm{~g} / \mathrm{l}$ of matrine and incubated for 12, 24 and $48 \mathrm{~h}$, respectively. The cell viability was measured by MTT assay. ${ }^{*} \mathrm{P}<0.05$ compared with the respective control.

\section{Results}

Growth inhibitory effect of matrine on lung cancer cells. Matrine has been previously shown to have an inhibitory effect on the growth of several cancer cell lines in vitro $(3,15-18,20,21,23-25)$. However, it has not been thoroughly explored whether the antitumor property of matrine is also effective on different lung cancer-derived cells. We first set out to examine the effects of matrine on the proliferation of lung cancer cell lines A549 and 95D. As shown in Fig. 2A and B, there was a significant reduction in the number of viable cells in correspondence to the increasing concentration of matrine used in the experiments. This holds true for the 12, 24 and $48 \mathrm{~h}$ observations; the reduction in cell viability was even more pronounced in the 48-h treatment group. After a $24-\mathrm{h}$ treatment with matrine at a concentration of 1.5 or $2.0 \mathrm{~g} / \mathrm{l}$, both A549 and 95D cells showed a $30 \%$ reduction in cell viability. The 48-h treatment with matrine further reduced the cell viability, especially at the higher concentrations, e.g. by an additional $20 \%$ at $2.0 \mathrm{~g} / 1$. Therefore, matrine treatment exerted a modest inhibitory effect on the growth of these two lung cancer cell lines in both a dose- and time-dependent manner.

Matrine induces the apoptosis of A549 cells. To ascertain that the reduction in viable cells post matrine treatment is the result of apoptosis, A549 cells were incubated with $1.0 \mathrm{~g} / \mathrm{l}$ matrine for $48 \mathrm{~h}$ and then examined by fluorescence microscopy. As shown in Fig. 3B, there were clear signs of chromatin condensation, nuclear fragmentation and the formation of apoptotic bodies in the matrine-treated cells (arrows), whereas the untreated A549 cells (Fig. 3A) showed mostly healthy nuclei. In line with the cell viability data, the percentage of matrine-treated cells showing apoptotic characteristics increased with higher concentrations of matrine used in the incubation (data not shown). Taken together, these results indicate that the cancer cell-killing mechanism of matrine involves apoptosis in A549 cells and it occurs in a dose-dependent manner.

In order to gain further insight into the dynamic progression from apoptosis to eventual cell death caused by matrine treatment, FACS analysis was employed to monitor the cell
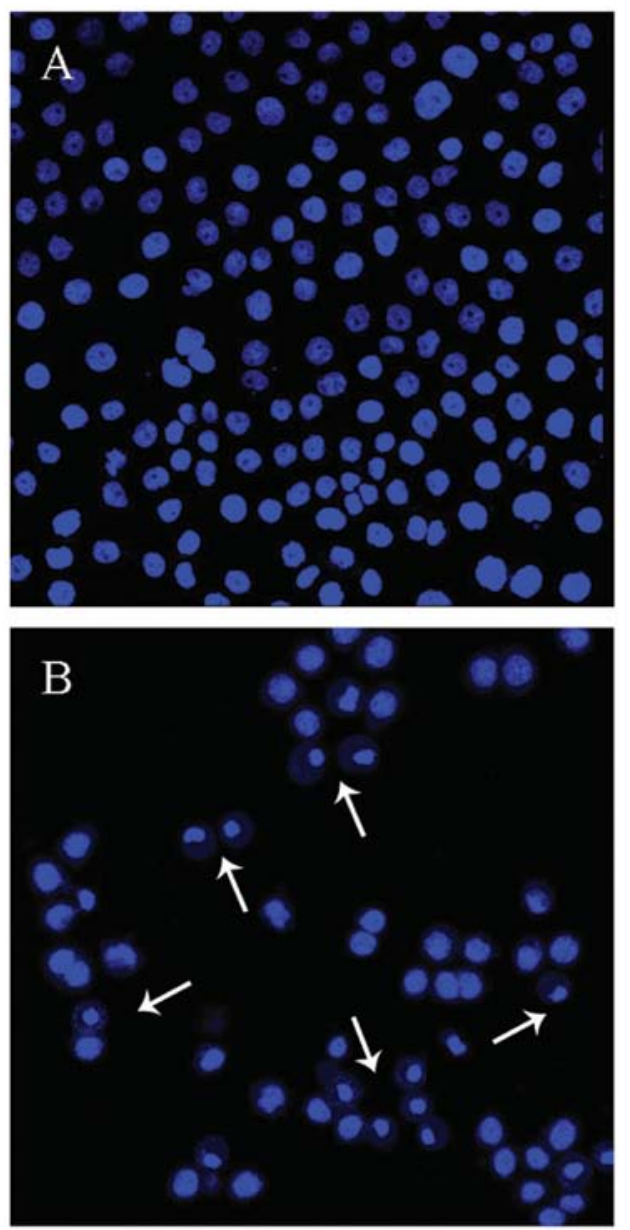

Figure 3. Matrine-induced apoptosis in A549 cells. A549 cell cultures of equivalent confluency were (A) untreated or (B) treated with $1.0 \mathrm{~g} / 1$ matrine and incubated for $48 \mathrm{~h}$, respectively. The nuclei of the cells were stained with Hoechst 33342, and apoptotic morphological changes were observed via fluorescence microscopy.

population undergoing apoptosis during matrine treatment. A549 cells were treated with different concentrations of matrine $(0,0.25,0.5,1.0,1.5$ and $2.0 \mathrm{~g} / 1$, respectively) for $48 \mathrm{~h}$ and were analyzed by flow cytometry. As shown in Fig. 4A, 

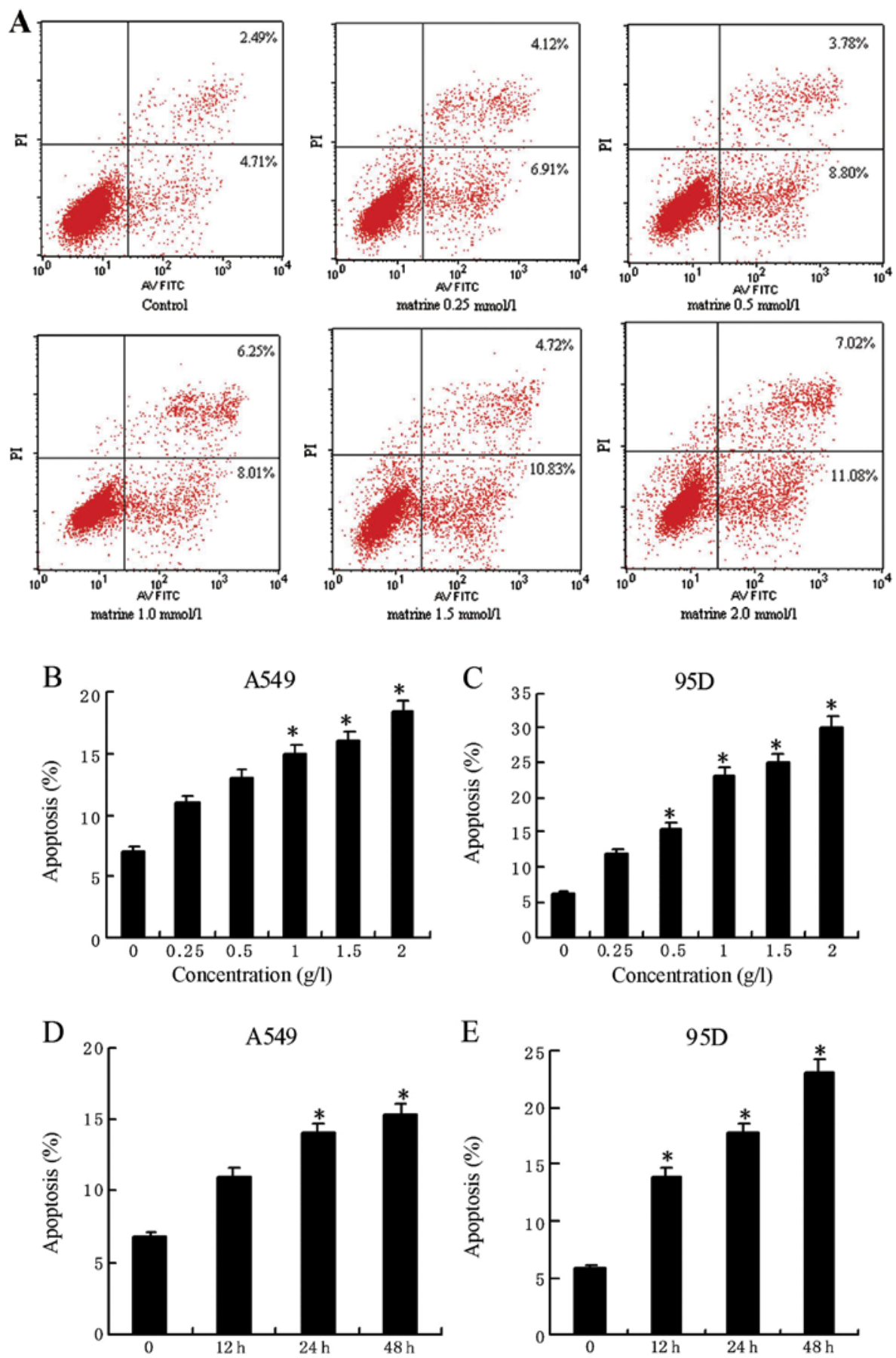

Figure 4. (A) FACS analysis of A549 cells treated with different concentrations of matrine. The percentage in the top right quadrant indicates the proportion of late apoptotic cells, whereas the percentage in the bottom right quadrant indicates the proportion of early apoptotic cells. Matrine induced apoptosis with various concentrations in (B) A549 and (C) 95D cells incubated for $48 \mathrm{~h}$, and in (D) A549 and (E) 95D cells treated with 1.0 g/l matrine for 12,24 and $48 \mathrm{~h}$. Values represent means $\pm \mathrm{SD}$ of three independent experiments. ${ }^{*} \mathrm{P}<0.05$, significantly different from the untreated control.

the numbers of both the early (bottom right quadrant) and late (top right quadrant) apoptotic cells increased significantly with regard to increasing concentrations of matrine used in the study $(\mathrm{P}<0.05)$. In contrast, the ratio between early and late (dead) apoptotic cells did not seem to change significantly in relation to the concentration of matrine, suggesting that the major effect of matrine occurs through the promotion of cancer cells to enter the apoptotic pathway, rather than at some stages during the apoptotic cascades. The pro-apoptotic effect of matrine was observed in both A549 and 95D cells in both a dose- and time-dependent manner (Fig. 4B-E).

Effect of matrine on early apoptotic processes. The fate of cells is determined dynamically by the competing pro- and anti-apoptotic processes involving members of the IAP (inhibitor of apoptosis) family. In order to better understand the molecular basis of matrine-induced apoptosis, we investigated the expression levels of members of the IAP family. A549 


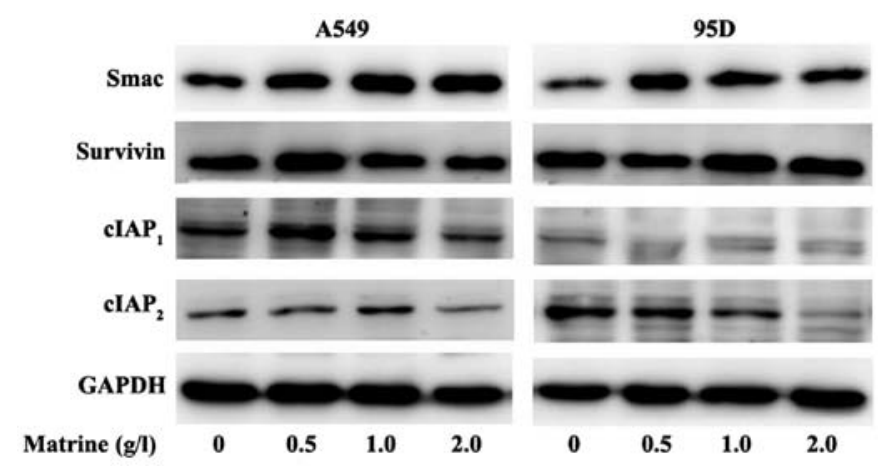

Figure 5. Expression levels of proteins regulating apoptotic pathways. Total cellular proteins were extracted from matrine-treated A549 and 95D cells and analyzed on SDS-PAGE followed by western blotting.

cells were treated with different concentrations of matrine $(0$, $0.5,1.0$ and $2.0 \mathrm{~g} / \mathrm{l}$ ) for $48 \mathrm{~h}$, and the total cellular proteins were extracted and analyzed on SDS-PAGE by western blotting. Interestingly, the level of Smac increased in concert with increasing concentrations of matrine in both A549 and 95D cells, hinting that matrine may actively promote pro-apoptotic processes (Fig. 5). Concomitantly, levels of cIAPs decreased in response to increasing concentrations of matrine, suggesting that matrine acted on the inhibition of anti-apoptotic processes (Fig. 5). The expression levels of survivin did not seem to change significantly in response to matrine treatment, however, its anti-apoptotic activity may have been blocked as a result of the inhibition of the Akt pathway (discussed below).

Matrine induces apoptosis in lung cancer cells through Akt inactivation. Activation of the Akt signaling pathway is one of the major mechanisms through which cancer cells promote cell survival. Our previous results indicated that the Akt pathway is involved not only in pathogenesis but also in drug-resistance of lung cancer (31). We were therefore interested in determining whether matrine treatment has any effect on the Akt pathway. As shown in Fig. 6, the expression levels of phosphorylated Akt (p-Akt) and total Akt (Akt) after treatment with various concentrations of matrine $(0,0.5,1.0,2.0 \mathrm{~g} / \mathrm{l})$ for $48 \mathrm{~h}$ decreased in a dose-dependent manner in response to increasing concentrations of matrine. Combined with our results concerning the matrine-induced reduction in cIAP expression, this result indicated that matrine may lower the anti-apoptotic activity of cIAPs via inhibiting the Akt pathway.

\section{Discussion}

Currently, the prognosis for inoperable or recurrent lung cancer patients remains dismal in spite of the development of novel chemotherapeutic strategies. While patients with early stage lung cancer can be potentially cured, most lung cancer patients are initially diagnosed at advanced stages. In addition, most advanced lung cancer patients are habitual smokers, whose health condition often leads to comorbidity in both cardiovascular and pulmonary systems, rendering aggressive surgery and multimodality therapy unfeasible. The severely unpleasant side-effects resulting from the standard care for advanced lung cancer can further reduce the quality of life of patients;

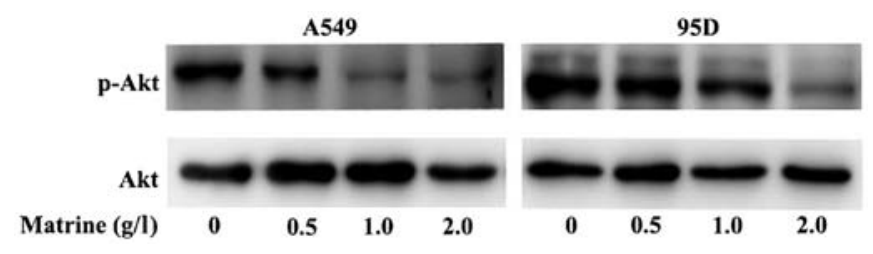

Figure 6. Expression levels of p-Akt and Akt proteins. Total cellular proteins were extracted from matrine-treated A549 and 95D cells and analyzed on SDS-PAGE followed by western blotting.

at times it may lead to therapy noncompliance. Urgently, the high prevalence and death rate of lung cancer cases in China calls for alternative therapeutics with improved effectiveness against the advanced stages and with lower toxicity.

The antitumor effect of matrine, an alkaloid extracted from Traditional Chinese herbal plants, has been studied in several cancer cell lines $(3,15-18,20,21,23-25)$. Matrine was found to inhibit the growth of cell lines derived from hepatoma, acute myeloid leukemia, melanoma, gastric carcinoma and lung cancer. Furthermore, matrine can inhibit the migration of lung cancer cells as well as that of human umbilical vein epithelial cells cultured in lung cancer cell conditioned media (32). The ability of matrine to inhibit the proliferation of cancer cells of many different types and origins suggests that it may act on a common pathway involved in the survival and growth of these cancer cells. Our finding that matrine inhibited the growth of both A549 and 95D lung cancer cells strongly supports this hypothesis.

Apoptosis, induced by chemotherapy, radiation and cytokines, is a major mechanism underlying the killing of tumor cells during cancer therapy. In this study, we found that apoptosis was also the point of action by which matrine prevents lung cancer cell growth. The proportion of both early and late apoptotic cells increased significantly after treatment of matrine at a concentration of $1.0 \mathrm{~g} / \mathrm{l}$ or higher. A few reports have implicated matrine in the induction of the pro-apoptotic pathways via lowering the ratio of Bcl-2/Bax (27) or by inhibiting human telomerase reverse transcriptase (hTERT), the catalytic subunit of telomerase (33). Activation of the phosphatidylinositol 3-kinase/Akt/mammalian target of rapamycin (PI3K-Akt-mTOR) signaling pathway has been observed in many types of tumors including lung cancer, which is considered to be important for the survival, proliferation, angiogenesis of cancer cells as well as their resistance to chemotherapy (34). Our previous results indicated that upregulation of the PI3K-Akt-mTOR pathway plays an important role in the growth and migration of lung cancer cells $(30,31)$. In particular, this pathway seems to be involved in the adapted tolerance of cancer cells to chemotherapeutic compounds such as docetaxel. The present study suggests that matrine can contribute to the effectiveness of chemotherapy by inhibiting the PI3K-Akt-mTOR pathway in lung cancer cells.

Second mitochondrial-derived activator of caspases (Smac) and inhibitor of apoptosis (IAP) family members, such as XIAP, c-IAP ${ }_{1}, \mathrm{c}-\mathrm{IAP}_{2}$ and survivin, are key regulators of apoptosis. In the cell, these factors promote competing pathways that ultimately determine the fate of the cell; Smac is pro-apoptotic and promotes cell death, IAPs are anti-apoptotic 
and promote cell survival. IAPs usually have three baculoviral IAP repeats (BIR) and a significant new gene (RING) zinc finger domain (35). BIR1, BIR2 and BIR3 domains are each capable of binding and inhibiting caspases independently and each also interacts with Smac; both interactions serve to halt the apoptotic cascade and promote cell survival. C-IAP1 and c-IAP2 are E3 ubiquitin ligases for Smac; they stimulate Smac degradation both in vivo and in vitro (36). Survivin, typically absent in most normal tissues, is often found to be highly expressed in fetal tissues, perpetuated cell lines and cancer cells (37-41). Clinically, overexpression of survivin in cancer is associated with the high propensity to metastasize and to develop resistance to chemotherapy; hence it is often considered as a biomarker for malignant characteristics of cancer (42-47). Consistent with the aforementioned hypothesis, matrine was found to upregulate the expression of Smac while downregulating the expression of IAPs. The expression of survivin did not seem to be significantly affected by the treatment of matrine; however, its anti-apoptotic activity was likely blocked due to the inhibition of the Akt pathway and the downregulation of cIAPs, which are known to stimulate the anti-apoptotic activity of survivin (48). Whether matrine acts directly or indirectly on these protein regulators of apoptosis remains an open question. Taken together, it hints at the notion that matrine may affect the expression of Akt, Bcl-2/Bax and Fas/FasL in various cancer cells, perhaps through a common mechanism. Identifying the direct target of matrine would help to delineate such a mechanism that links the PI3K-Akt-mTOR pathway with the apoptosis cascades.

Our results reported here substantiated the therapeutic potential of matrine in lung cancer treatment. Given the dosage of matrine used in TCM concoctions, concentrations of matrine used in the present study should be well tolerated by the human body. In a mouse model for squamous cell carcinoma, matrine was administered at a dosage of $250 \mathrm{~g} / \mathrm{kg}$ with no apparent adverse impact on health (49). Furthermore, it has been reported that matrine could ease the pain of cancer patients receiving chemotherapy, enhance the body's immunity and protect major organs such as the heart, liver and kidney from being damaged by chemicals/drugs during chemotherapy (50-52), all of which could help improve the quality of life of lung cancer patients receiving chemotherapy.

Clinically, lung cancer manifests in different forms, and the underlying biology dictates the progression and malignancy of the cancer such as the propensity to metastasize and to be resistant to conventional therapies. While matrine has shown some promise in several types of lung cancer in a tissue culture system, it does not seem to kill cancer cells completely. This may be due to the low concentration of matrine used in our experiments. On the other hand, these data suggest that probably the most effective use of matrine in lung cancer treatment is as an adjuvant. Investigation of whether there exists any additive and/or synergistic therapeutic benefits when applying a combination of matrine and conventional chemotherapies to treat cancer cell cultures or in animal models is warranted.

Our findings reported here corroborate previous results that reveal matrine-induced anticancer activity in tissue culture systems. The cancer-killing effect is likely through inhibition of the PI3K-Akt-mTOR pathway and promotion of apoptosis via downregulation of cIAPs. Given the prevalence of the deregulated PI3K-Akt-mTOR pathway and overexpression of cIAPs in many types of cancer, perhaps it is not surprising to find that matrine is effective in killing a spectrum of cancer cells of varying origins. A better understanding of the molecular basis of matrine-induced apoptosis in lung cancer cells may not only shed light on the pathogenesis of NSCLC but may also contribute to the development of more effective combination therapies for the treatment of advanced stage lung cancer.

\section{Acknowledgements}

This study was supported by a grant from the National Natural Science Foundation of China (no. 81201832), the Outstanding Scientific Fund of Shengjing Hospital and Specialized Research Fund for the Doctoral Program of Higher Education (no. 20122104110011).

\section{References}

1. Jemal A, Bray F, Center MM, Ferlay J, Ward E and Forman D: Global cancer statistics. CA Cancer J Clin 61: 69-90, 2011.

2. Molina JR, Yang P, Cassivi SD, Schild SE and Adjei AA: Non-small cell lung cancer: epidemiology, risk factors, treatment, and survivorship. Mayo Clin Proc 83: 584-594, 2008.

3. Zhang Y, Zhang H, Yu P, et al: Effects of matrine against the growth of human lung cancer and hepatoma cells as well as lung cancer cell migration. Cytotechnology 59: 191-200, 2009.

4. Efferth T, Konkimalla VB, Wang YF, et al: Prediction of broad spectrum resistance of tumors towards anticancer drugs. Clin Cancer Res 14: 2405-2412, 2008.

5. Dong J, Su SY, Wang MY and Zhan Z: Shenqi fuzheng, an injection concocted from Chinese medicinal herbs, combined with platinum-based chemotherapy for advanced non-small cell lung cancer: a systematic review. J Exp Clin Cancer Res 29: 137, 2010.

6. Liu XS, Jiang J, Jiao XY, Wu YE and Lin JH: Matrine-induced apoptosis in leukemia U937 cells: involvement of caspases activation and MAPK-independent pathways. Planta Med 72: 501-506, 2006.

7. Zhang HM and Li HQ: Anti-arrhythmic effects of sophoridine and oxysophoridine. Zhongguo Yao Li Xue Bao 20: 517-520, 1999.

8. Ai J, Gao HH, He SZ, Wang L, Luo DL and Yang BF: Effects of matrine, artemisinin, tetrandrine on cytosolic $\left[\mathrm{Ca}^{2+}\right] \mathrm{i}$ in guinea pig ventricular myocytes. Acta Pharmacol Sin 22: 512-515, 2001.

9. Xu CQ, Dong DL, Du ZM, Chen QW, Gong DM and Yang BF: Comparison of the anti-arrhythmic effects of matrine and berbamine with amiodarone and RP58866. Yao Xue Xue Bao 39: 691-694, 2004 (In Chinese).

10. Hu ZL, Zhang JP, Yu XB, Lin W, Qian DH and Wan MB: Effect of matrine on lipopolysaccharides/D-galactosamine-induced hepatitis and tumor necrosis factor release from macrophages in vitro. Zhongguo Yao Li Xue Bao 17: 351-353, 1996 (In Chinese).

11. Liu J, Zhu M, Shi R and Yang M: Radix Sophorae flavescentis for chronic hepatitis B: a systematic review of randomized trials. Am J Chin Med 31: 337-354, 2003.

12. Long Y,Lin XT, Zeng KL and Zhang L: Efficacy of intramuscular matrine in the treatment of chronic hepatitis B. Hepatobiliary Pancreat Dis Int 3: 69-72, 2004.

13. Gao HY, Li GY, Lou MM, Li XY, Wei XY and Wang JH: Hepatoprotective effect of matrine salvianolic acid B salt on carbon tetrachloride-induced hepatic fibrosis. J Inflamm 9: 16, 2012.

14. Liu JY, Hu JH, Zhu QG, Li FQ, Wang J and Sun HJ: Effect of matrine on the expression of substance $\mathrm{P}$ receptor and inflammatory cytokines production in human skin keratinocytes and fibroblasts. Int Immunopharmacol 7: 816-823, 2007.

15. Li H, Tan G, Jiang X, et al: Therapeutic effects of matrine on primary and metastatic breast cancer. Am J Chin Med 38: 1115-1130, 2010.

16. Li LQ, Li XL, Wang L, et al: Matrine inhibits breast cancer growth via miR-21/PTEN/Akt pathway in MCF-7 cells. Cell Physiol Biochem 30: 631-641, 2012. 
17. Liu T, Song Y, Chen H, Pan S and Sun X: Matrine inhibits proliferation and induces apoptosis of pancreatic cancer cells in vitro and in vivo. Biol Pharm Bull 33: 1740-1745, 2010.

18. Luo C, Zhong HJ, Zhu LM, et al: Inhibition of matrine against gastric cancer cell line MNK45 growth and its anti-tumor mechanism. Mol Biol Rep 39: 5459-5464, 2012.

19. Yang CL, Liu SS, Ma YG, Liu YY, Xue YX and Huang B: The influence of intraoperative pleural perfusion with matrine-cisplatin or cisplatin on stromal cell-derived factor-1 in non-small cell lung cancer patients with subclinical pleural metastasis. Med Oncol 29: 574-581, 2012.

20. Zhang J, Li Y, Chen X, et al: Autophagy is involved in anticancer effects of matrine on SGC-7901 human gastric cancer cells. Oncol Rep 26: 115-124, 2011

21. Chui CH, Lau FY, Tang JC, et al: Activities of fresh juice of Scutellaria barbata and warmed water extract of Radix Sophorae Tonkinensis on anti-proliferation and apoptosis of human cancer cell lines. Int J Mol Med 16: 337-341, 2005.

22. Hu MJ, Zeng H, Wu YL, et al: Synergistic effects of matrine and 5 -fluorouracil on tumor growth of the implanted gastric cancer in nude mice. Chin J Dig Dis 6: 68-71, 2005.

23. Luo C, Zhu Y, Jiang T, et al: Matrine induced gastric cancer MKN45 cells apoptosis via increasing pro-apoptotic molecules of Bcl-2 family. Toxicology 229: 245-252, 2007.

24. Ma L, Wen S, Zhan Y, He Y, Liu X and Jiang J: Anticancer effects of the Chinese medicine matrine on murine hepatocellular carcinoma cells. Planta Med 74: 245-251, 2008.

25. Yu P, Liu Q, Liu K, Yagasaki K, Wu E and Zhang G: Matrine suppresses breast cancer cell proliferation and invasion via VEGF-Akt-NF-kappaB signaling. Cytotechnology 59: 219-229, 2009.

26. Dai ZJ, Gao J, Ji ZZ, et al: Matrine induces apoptosis in gastric carcinoma cells via alteration of Fas/FasL and activation of caspase-3. J Ethnopharmacol 123: 91-96, 2009.

27. Zhang S, Zhang Y, Zhuang Y, et al: Matrine induces apoptosis in human acute myeloid leukemia cells via the mitochondrial pathway and Akt inactivation. PLoS One 7: e46853, 2012.

28. Liang CZ, Zhang JK, Shi Z, Liu B, Shen CQ and Tao HM: Matrine induces caspase-dependent apoptosis in human osteosarcoma cells in vitro and in vivo through the upregulation of Bax and Fas/FasL and downregulation of Bcl-2. Cancer Chemother Pharmacol 69: 317-331, 2012.

29. Jiang H, Hou C, Zhang S, et al: Matrine upregulates the cell cycle protein $\mathrm{E} 2 \mathrm{~F}-1$ and triggers apoptosis via the mitochondrial pathway in K562 cells. Eur J Pharmacol 559: 98-108, 2007.

30. Niu H, Li H, Xu C and He P: Expression profile of RhoGDI2 in lung cancers and role of RhoGDI 2 in lung cancer metastasis. Oncol Rep 24: 465-471, 2010.

31. Niu H, Wang J, Li H and He P: Rapamycin potentiates cytotoxicity by docetaxel possibly through downregulation of survivin in lung cancer cells. J Exp Clin Cancer Res 30: 28, 2011.

32. Lu J, Luo Q, Cheng P, Liu X, Bai M and Tu M: The role of matrine and mitogen-ativated protein kinase/extracellular signal-regulated kinase signal transduction in the inhibition of the proliferation and migration of human umbilical veins endothelial cells induced by lung cancer cells. Zhongguo Fei Ai Za Zhi 12: 747-752, 2009 (In Chinese).

33. Chen Q, Liu L and Cao H: Effects of matrine on the growth inhibition, c-myc and hTERT protein expression in human adenocarcinoma lung cancer cell line A549. Zhongguo Fei Ai Za Zhi 11: 559-562, 2008 (In Chinese).
34. Nicholson KM and Anderson NG: The protein kinase B/Akt signalling pathway in human malignancy. Cell Signal 14: 381-395, 2002.

35. Deveraux QL and Reed JC: IAP family proteins - suppressors of apoptosis. Genes Dev 13: 239-252, 1999.

36. Hu S and Yang X: Cellular inhibitor of apoptosis 1 and 2 are ubiquitin ligases for the apoptosis inducer Smac/DIABLO.J Biol Chem 278: 10055-10060, 2003.

37. Altieri DC: The molecular basis and potential role of survivin in cancer diagnosis and therapy. Trends Mol Med 7: 542-547, 2001.

38. Marioni G, Bertolin A, Giacomelli L, et al: Expression of the apoptosis inhibitor protein survivin in primary laryngeal carcinoma and cervical lymph node metastasis. Anticancer Res 26: 3813-3817, 2006.

39. Osaka E, Suzuki T, Osaka S, et al: Survivin as a prognostic factor for osteosarcoma patients. Acta Histochem Cytochem 39: 95-100, 2006.

40. Tran J, Rak J, Sheehan C, et al: Marked induction of the IAP family antiapoptotic proteins survivin and XIAP by VEGF in vascular endothelial cells. Biochem Biophys Res Commun 264: 781-788, 1999.

41. Harfouche R, Hassessian HM, Guo Y, et al: Mechanisms which mediate the antiapoptotic effects of angiopoietin-1 on endothelial cells. Microvasc Res 64: 135-147, 2002.

42. Als AB, Dyrskjot L, von der Maase H, et al: Emmprin and survivin predict response and survival following cisplatin-containing chemotherapy in patients with advanced bladder cancer. Clin Cancer Res 13: 4407-4414, 2007.

43. Hinnis AR, Luckett JC and Walker RA: Survivin is an independent predictor of short-term survival in poor prognostic breast cancer patients. Br J Cancer 96: 639-645, 2007.

44. Nakagawa Y, Abe S, Kurata M, et al: IAP family protein expression correlates with poor outcome of multiple myeloma patients in association with chemotherapy-induced overexpression of multidrug resistance genes. Am J Hematol 81: 824-831, 2006

45. Watanuki-Miyauchi R, Kojima Y, Tsurumi H, et al: Expression of survivin and of antigen detected by a novel monoclonal antibody, T332, is associated with outcome of diffuse large B-cell lymphoma and its subtypes. Pathol Int 55: 324-330, 2005.

46. Schlette EJ, Medeiros LJ, Goy A, Lai R and Rassidakis GZ: Survivin expression predicts poorer prognosis in anaplastic large-cell lymphoma. J Clin Oncol 22: 1682-1688, 2004.

47. Adida C, Haioun C, Gaulard P, et al: Prognostic significance of survivin expression in diffuse large B-cell lymphomas. Blood 96: 1921-1925, 2000.

48. Altieri DC: Survivin, cancer networks and pathway-directed drug discovery. Nat Rev Cancer 8: 61-70, 2008.

49. Wang Y, Zhang Z, Garbow JR, et al: Chemoprevention of lung squamous cell carcinoma in mice by a mixture of Chinese herbs. Cancer Prev Res 2: 634-640, 2009.

50. Liu Y, Xu Y, Ji W, et al: Anti-tumor activities of matrine and oxymatrine: literature review. Tumour Biol: Feb 14, 2014 (Epub ahead of print).

51. Linglu D, Yuxiang L, Yaqiong X, et al: Antinociceptive effect of matrine on vincristine-induced neuropathic pain model in mice. Neurol Sci: Dec 14, 2013 (Epub ahead of print).

52. Haiyan W, Yuxiang L, Linglu D, et al: Antinociceptive effects of matrine on neuropathic pain induced by chronic constriction injury. Pharm Biol 51: 844-850, 2013. 